\title{
Prognostic role of EGFR gene copy number and KRAS mutation in patients with locally advanced rectal cancer treated with preoperative chemoradiotherapy
}

\author{
C Bengala*,', S Bettelli', F Bertolini', G Sartori², A Fontana', N Malavasi', R Depenni', S Zironi', \\ C Del Giovane', G Luppi' and PF Conte'
}

'Division of Medical Oncology, Department of Oncology, Hematology and Respiratory Disease, University Hospital, University of Modena and Reggio Emilia, Via del Pozzo, 7 I, Modena - 41 1 00, Italy; ${ }^{2}$ Institute of Pathology and Cell Biology, Department of Laboratories, Pathology and Forensic Medicine, University Hospital, University of Modena and Reggio Emilia, Via del Pozzo, 71 , Modena - 4l 100, Italy

\begin{abstract}
BACKGROUND: Epidermal growth factor receptor (EGFR), evaluated by immunohistochemistry, has been shown to have prognostic significance in patients with colorectal cancer. Gene copy number (GCN) of EGFR and KRAS status predict response and outcome in patients treated with anti-EGFR therapy, but their prognostic significance in colorectal cancer patients is still unclear.

METHODS: We have retrospectively reviewed the baseline EGFR GCN, KRAS status and clinical outcome of I 46 locally advanced rectal cancer (LARC) patients treated with preoperative chemoradiotherapy. Pathological response evaluated by Dworak's tumour regression grade (TRG), disease-free survival (DFS) and overall survival (OS) were analysed.

RESULTS: Tumour regression grade 4 and TRG3-4 were achieved in 14.4 and 30.8\% of the patients respectively. Twenty-nine (19.9\%) and 33 patients (19.2\%) had an EGFR/nuclei ratio $>2.9$ and CEP7 polisomy > 50\% respectively; 28 patients (19.2\%) had a KRAS mutation. Neither EGFR GCN nor KRAS status was statistically correlated to TRG. 5-year DFS and OS were 63.3 and 71.5\%, respectively, and no significant relation with EGFR GCN or KRAS status was found.

CONCLUSION: Our data show that EGFR GCN and KRAS status are not prognostic factors in LARC treated with preoperative chemoradiation.

British Journal of Cancer (2010) 103, 1019-1024. doi:10.1038/sj.bjc.6605853 www.bjcancer.com

Published online 14 September 2010

(c) 2010 Cancer Research UK
\end{abstract}

Keywords: rectal cancer; neoadjuvant chemoradiotherapy; EGFR; KRAS

Epidermal growth factor receptor (EGFR) protein expression, evaluated by immunohistochemistry (IHC), has been shown to have prognostic significance in patients with colon cancer (Watanabe et al, 2001). In locally advanced rectal cancer (LARC) treated with preoperative chemoradiotherapy (CTRT), baseline EGFR (IHC) expression predicts a poor tumour downstaging (Kim et al, 2006) and is also an independent prognostic factor for local recurrence (Azria et al, 2005; Giralt et al, 2005; Li et al, 2006). Moreover, we have shown that EGFR expression on the residual tumour after neoadjuvant CTRT is an independent prognostic parameter for disease-free survival (DFS; Bertolini et al, 2007). However, IHC is a semi-quantitative method that lacks a standardised immunostaining and scoring system and is subject to inter-observer variation (Atkins et al, 2004; Shia et al, 2005). EGFR gene copy number (GCN) determined by FISH has been proposed as a more reliable assay than IHC to determine the sensitivity of anti-EGFR drugs (Chung et al, 2005; Moroni et al, 2005; Cappuzzo et al, 2008) but the prognostic role of EGFR $\mathrm{GCN}$ is unclear.

*Correspondence: Dr C Bengala; E-mail: carmelo.bengala@unimore.it Revised 24 June 20I0; accepted 20 July 2010; published online 14 September 2010
KRAS mutation status has been shown to be a predictive factor for response to anti-EGFR monoclonal antibodies in metastatic colorectal cancer (Bokemeyer et al, 2009; Van Cutsem et al, 2009) and, recently, KRAS wild-type status has been recognised by the US FDA and EMEA as a predictive factor to select patients candidate to receive cetuximab or panitumumab. We have also shown that EGRF GCN and KRAS mutation status correlate with pathological response to preoperative chemoradiation and cetuximab in LARC (Bengala et al, 2009).

To further explore the prognostic and predictive role of EGFR GCN and KRAS mutation status, we have analysed our database of patients with LARC treated with preoperative radiation therapy and fluoropyrimidine-based chemotherapy. Objectives of the study were to correlate the GCN and KRAS status with the pathological response according to Dworak's tumour regression grade (TRG), DFS and overall survival (OS).

\section{MATERIALS AND METHODS}

\section{Patients and treatment}

We have retrospectively analysed data of 146 patients with LARC who were treated with preoperative chemotherapy at our 
institution between May 1998 and October 2005. The treatment included pelvic radiotherapy (2 Gy per fraction for 25 fractions) in a large pelvic field involving the tumour mass and regional lymph nodes, and concomitant chemotherapy with continuous infusion 5-fluorouracile (5-FU) with or without oxaliplatin or capecitabine. 5 -Fluorouracil was administered at the dose of $225 \mathrm{mg} \mathrm{m}^{-2}$ per day as i.v. continuous infusion 7 days a week for 5 weeks; capecitabine was administered at $825 \mathrm{mg} \mathrm{m}^{-2}$ b.i.d. continuously for all the duration of radiotherapy; oxaliplatin was administered at $60 \mathrm{mg} \mathrm{m}^{-2}$ weekly in combination with 5 -FU $225 \mathrm{mg} \mathrm{m}^{-2}$ per day as i.v. continuous infusion 7 days a week for 5 weeks. Surgery was performed 6-8 weeks after the end of combined treatment. A more detailed report of the staging procedure and treatment plan has been already published (Gavioli et al, 2005).

\section{Tissue samples and pathology assessment}

All patients underwent tumour biopsy for diagnostic purpose before starting the treatment. Several $3 \mu \mathrm{m}$-thick sections were obtained from a representative formalin-fixed and paraffinembedded block where the neoplastic component was at least the $80 \%$ of the tissue. At the time of surgery, pathologic evaluation in the resection specimens included TNM categories, stage grouping, number of examined/involved lymph nodes and tumour differentiation. All pathological and molecular assessments were performed by dedicated pathologists at our University Hospital. Tumour regression was semi-quantitatively determined by the amount of viable tumour $v s$ the amount of fibrosis, as described by Dworak et al (1997) and validated by Rodel et al (2005). Tumour regression grade 0 was defined as no regression; TRG1, minor regression (dominant tumour with fibrosis in $\leqslant 25 \%$ of the tumour mass); TRG2, moderate regression (dominant tumour with fibrosis in $26-50 \%$ of the tumour mass); TRG3, good regression (more than $50 \%$ tumour regression) and TRG4, total regression (no viable tumour cells, only fibrotic mass).

\section{EGFR FISH}

Fluorescence in situ hybridisation (FISH) studies were performed on selected sections of paraffin-embedded tissue areas, containing representative malignant cells, using the LSI EGFR Spectrum Orange/CEP7SpectrumGreen probe (Vysis Inc., Downer's Grove, IL, USA). Tissue sections of $4 \mu \mathrm{m}$ thickness were placed on electrostatically charged slides, air dried and baked overnight at $56^{\circ} \mathrm{C}$. The slides were de-waxed in xylene for $2 \times 15 \mathrm{~min}$, immersed in $100 \%$ ethanol for $2 \times 5 \mathrm{~min}$ and in $95 \%$ ethanol for $2 \times 5 \mathrm{~min}$. Air-dried tissue sections were treated with a Paraffin Pretreatment Kit (Vysis Inc.). The slides were briefly incubated in $0.2 \mathrm{moll}^{-1}$ $\mathrm{HCl}$ for $20 \mathrm{~min}$, washed with Wash Buffer, incubated for $30 \mathrm{~min}$ at $80^{\circ} \mathrm{C}$ with Pretreatment Solution (NaSCN), washed with Wash Buffer and finally treated in a Protease I solution $\left(0.5 \mathrm{mg} \mathrm{ml}^{-1}\right.$ protease buffer; $\mathrm{pH}$ 2) for $10-12 \mathrm{~min}$ at $37^{\circ} \mathrm{C}$.

After adding $10 \mu \mathrm{l}$ of the hybridisation probe and placing a coverslip, denaturation and hybridisation of DNA was performed using the metal block of a thermocycler (HyBrite; Vysis Inc.). The denaturation was carried out at $83^{\circ} \mathrm{C}$ for $3 \mathrm{~min}$ and the hybridisation was carried out overnight at $37^{\circ} \mathrm{C}$. After hybridisation the excess of the probes was washed in $2 \times \mathrm{SSC} / 0.3 \% \mathrm{NP}-40$ at $73^{\circ} \mathrm{C}$ for $2 \mathrm{~min}$. The nuclei were counterstained with $1000 \mathrm{ng} \mathrm{ml}^{-1}$ DAPI/Antifade (4.6-diamidine-2-phenyl indole; Vysis Inc.). For the scoring, a Zeiss Axioscope fluorescence microscope (Carl Zeiss Inc., Jena, Germany) was used, equipped with a specially designed filter combination: the EGFR sequence was visualised with a Orange filter, the chromosome 7 centromere sequence was visualised with a Green filter and the nuclei were identified with a DAPI filter. A triple band pass filter (Orange, Green and DAPI; Vysis Inc.) was also used. Hybridisation signals were scored in at least 200 intact non-overlapping nuclei and FISH analysis was performed independently by two observers using constant adjustment of microscope focus because signals were located at different focal planes. Representative images of each specimen were acquired with a high-performance CCD camera in monochromatic layers that were subsequently merged by the Quips PathVysion Software (Vysis Inc.).

Epidermal growth factor receptor gene status was scored as the average number of EGFR red signals per nucleus and as the ratio between EGFR red signals and CEP7 green signals. Polisomy of EGFR gene was defined as an increase of EGFR red signals $(\geqslant$ three signals per nucleus) paralleled by the same increase of chromosomes 7 (where the EGFR gene is located) as measured by the number of CEP 7 green signals per nucleus. High GCN was defined as EGFR/nuclei ratio $\geqslant 2.9$ or an EGFR/CEP7 polysomy $>3$ in at least $50 \%$ of the cells. All cases were scored and reviewed by two observers (SB and NB) and inter-observer disagreement was discussed in an institutional meeting.

\section{DNA extraction and KRAS mutation analysis}

KRAS mutation status was analysed at the Laboratory of Cell Biology of the Department of Pathology, University of Modena and Reggio Emilia, Modena, Italy.

Three haemaxytolin-eosin-stained sections ( $5 \mu \mathrm{m}$ thick) from a representative paraffin-embedded block were applied on noncover-slipped slides for microdissection and DNA extraction. Briefly, microdissection was performed under direct observation with an inverted microscope using a sterile needle. Each microdissected sample was directly transferred to an Eppendorf tube containing digestion buffer $\left(2 \mathrm{mg} \mathrm{ml}^{-1}\right.$ proteinase $\mathrm{K}$ in $50 \mathrm{~mm}$ Tris (pH 8.5), 1 mM EDTA, $0.5 \%$ Tween 20 ). The tubes were then incubated overnight at $56^{\circ} \mathrm{C}$, and followed by $10 \mathrm{~min}$ of incubation at $95^{\circ} \mathrm{C}$ to eliminate any remaining proteinase $\mathrm{K}$ activity. PCR was performed in $20 \mu \mathrm{l}$ reactions containing $2.0 \mu \mathrm{l}$ DNA, $2 \mu \mathrm{l}$ commercial PCR buffer (Applied Biosystems, Foster City, CA, USA), $2.0 \mathrm{~mm}$ of $\mathrm{MgCl}_{2}, 200 \mathrm{~mm}$ of each dNTP, $20 \mathrm{pmol}$ of each primer, and $3 \mathrm{U}$ AmpliTaq Gold polymerase (Applied Biosystems). PCR reaction was carried out on Uno II Thermoblock (Biometra, Gottingen, Germany). Initial denaturation at $95^{\circ} \mathrm{C}$ for $10 \mathrm{~min}$ was followed by 41 cycles, and a final extension step $\left(10 \mathrm{~min}\right.$ at $\left.72^{\circ} \mathrm{C}\right)$. The cycles included denaturation at $95^{\circ} \mathrm{C}$ for $1 \mathrm{~min}$, annealing at $52^{\circ} \mathrm{C}$ for $1 \mathrm{~min}$ and extension at $72^{\circ} \mathrm{C}$ for $2 \mathrm{~min}$. Exon 2 of KRAS was PCR amplified using intron-based primers to investigate the mutational status of KRAS codons 12 and 13, because it is frequently founded mutated in colorectal cancer. The forward and reverse oligonucleotide primers used to amplify KRAS exon 2 were: forward, $5^{\prime}$-CATGTTCTAATATAGTCACA-3'; reverse, $5^{\prime}$-AACAAGATTTACCTCTATTG- $3^{\prime}$.

The amplified DNA was electrophoresed on $2 \%$ agarose gel for $1 \mathrm{~h}$ at $110 \mathrm{~V}$. The amplification products were then purified by using MinElute PCR purification Kit (Qiagen, Valencia, CA, USA) as indicated by the manufacturer. PCR products were then amplified in both directions with ABI Prism BigDye Terminator version 1.1 Cycle Sequencing kit (Applied Biosystems), using the same primers as those used for PCR. PCR products were finally purified by Centri-Sep Spin Columns (Applied Biosystems) and subsequently ran on the ABI Prism 310 Automatic Sequencer (Applied Biosystems). The data were analysed with the Sequencing Analysis 5.2 software (Applied Biosystems).

\section{Statistical analysis}

The study, including the molecular analysis, was approved by the ethical committee of the Province of Modena.

Tumour downstaging and the pathological response, based on Dworak's TRG, were associated with biological characteristics with Fisher's exact test. 
Disease-free survival was defined as the interval from the date of diagnosis until the date of tumour recurrence, second primary tumour or death with or without recurrence. Overall survival was defined as the date of study entry until the date of death. The DFS and OS curves were calculated according to the Kaplan-Meier method. Long-rank test was used to compare DSF and OS according to pathological response and tumour biomarkers.

Hazard ratios and 95\% confidence intervals for recurrence or death were calculated to evaluate the association with the pathological response and the tumour biomarkers using the univariate Cox proportional hazard model.

Statistical significance was set at $P<0.05$. All the analyses were conducted using STATA 10.0 (College Station, TX, USA).

Table I Patient characteristics

\begin{tabular}{|c|c|c|}
\hline \multirow{3}{*}{$\begin{array}{l}\text { Number of patients } \\
\text { Median age, years (range) } \\
\text { Characteristic }\end{array}$} & \multicolumn{2}{|c|}{146} \\
\hline & \multicolumn{2}{|c|}{$64(26-78)$} \\
\hline & $N$ & $\%$ \\
\hline \multicolumn{3}{|l|}{ Gender } \\
\hline Male & 86 & 58.9 \\
\hline Female & 60 & 48.1 \\
\hline PS (ECOG scale) & 0 & 100 \\
\hline \multicolumn{3}{|l|}{ Clinical stage } \\
\hline UT2NI & 5 & 3.4 \\
\hline UT3NO & 48 & 32.9 \\
\hline UT3NI & 63 & 43.2 \\
\hline UT4NO & 11 & 7.5 \\
\hline UT4NI & 15 & 10.3 \\
\hline Any TNMI & 4 & 2.7 \\
\hline \multicolumn{3}{|l|}{ Chemotherapy concurrent to RT } \\
\hline $5-F U$ & 98 & 67.1 \\
\hline 5-FU+Oxaliplatin & 34 & 23.3 \\
\hline Capecitabine & 14 & 9.6 \\
\hline \multicolumn{3}{|l|}{ EGFR/nuclei ratio } \\
\hline$<2.9$ & 115 & 78.8 \\
\hline$\geqslant 2.9$ & 29 & 19.9 \\
\hline NA & 2 & 1.4 \\
\hline \multicolumn{3}{|l|}{ CEP7 polisomy ( $>3$ copies) } \\
\hline$<50 \%$ & 110 & 75.3 \\
\hline$\geqslant 50 \%$ & 33 & 22.6 \\
\hline NA & 3 & 2.1 \\
\hline \multicolumn{3}{|l|}{ KRAS } \\
\hline Wild type & 116 & 79.5 \\
\hline Mutated & 28 & 19.2 \\
\hline NA & 2 & 1.4 \\
\hline \multicolumn{3}{|c|}{ Pathological response (Dworak's grade) } \\
\hline TRG 4 & 21 & 14.4 \\
\hline TRG 3 & 24 & 16.4 \\
\hline TRG 2 & 46 & 31.5 \\
\hline TRG I & 48 & 32.9 \\
\hline TRG 0 & 3 & 2.1 \\
\hline NA & 4 & 2.7 \\
\hline \multicolumn{3}{|l|}{ Downstaging } \\
\hline Yes & 85 & 58.2 \\
\hline Not & 55 & 37.7 \\
\hline NA & 6 & 4.1 \\
\hline
\end{tabular}

Abbreviations: $\mathrm{ECOG}=$ eastern cooperative oncology group; $\mathrm{EGFR}=$ epidermal growth factor receptor; 5 -FU = 5-fluorouracile; $\mathrm{NA}=$ not available; $\mathrm{PS}=$ performance status; TRG = tumour regression grade.

\section{RESULTS}

Patient characteristics are described in Table 1. Median age was 64 years (range 26-78). At diagnosis, clinical stage defined with ultrasonography was stage II in 59 patients (IIA 48 patients, IIB 11 patients), stage III in 83 patients (IIIA 5 patients, IIIB 78 patients) and stage IV in 4 patients. All the patients received pelvic radiation therapy; concomitant chemotherapy was 5-FU in 98 patients $(67.1 \%), 5-\mathrm{FU}$ in combination with oxaliplatin in 34 patients $(23.3 \%)$ and capecitabine in 14 patients $(9.6 \%)$. A pathological complete response classified as Dworak's TRG4 was achieved in 21 patients (14.4\%); a TRG3 was observed in 24 patients $(16.4 \%)$, TRG2 in 46 patients (31.5\%); TRG1 in 48 patients (32.9\%), TRG0 in 3 patients $(2.1 \%)$. Tumour and lymph node downstaging was observed in 85 patients $(58.2 \%)$.

\section{Biomarker expression and response}

EGFR GCN was evaluated as EGFR/nuclei ratio and as CEP7 polisomy. Median EGFR/nuclei ratio was 2.3 (range 1.1-3.5). Median CEP7 polisomy was $28.3 \%$ (range 0-78\%). A high EGFR/ nuclei ratio $(\geqslant 2.9)$ and a low EGFR/nuclei ratio $(<2.9)$ was present in 19.9 and $78.8 \%$ patients respectively; a high CEP7 polisomy $(\geqslant 50 \%)$ and a low polisomy $(<50 \%)$ was observed in 22.6 and $75.3 \%$ patients respectively. Among the 113 assessable patients with low EGFR/nuclei ratio, $15(13.3 \%)$ and $36(31.3 \%)$ had a TRG4 and TRG3-4 respectively, compared with $6(22.2 \%)$ and $9(33.3 \%)$ of the 27 assessable patients with high EGFR/nuclei ratio $(P=0.19$ and 0.53$)$. Moreover, $14(12.7 \%)$ and $36(32.7 \%)$ of the 110 assessable patients with low CEP7 polisomy had a TRG4 and TRG3 - 4 respectively, compared with $7(23.3 \%)$ and $9(30.0 \%)$ of the 30 patients with high CEP7 polisomy $(P=0.13$ and 0.48$)$ (Table 2).

The downstaging rate was $59.6 v s 65.5 \%$ in patients with low and high EGFR/nuclei ratio respectively $(P=0.36)$ and 64.8 and $48.5 \%$ in patients with low and high CEP7 polisomy respectively $(P=0.07)$ (Table 2).

A wild-type KRAS was reported in $79.5 \%$ of the patients and in these patients the rate of TRG4 was $16.7 \%$; a mutated KRAS was found in $19.2 \%$ of the patients with a TRG4 of $7.4 \%$; this difference is not significant $(P=0.18)$. The rate of TRG3-4 was higher in wild-type KRAS (35.1\%) in comparison to mutated status (18.5\%) and this difference approaches a statistical significance $(P=0.07)$ (Table 2).

\section{Biomarker expression and survival}

At a median follow-up of 4.45 years (range $0.29-10.6$ ), median DFS was 8 years (range $0.27-10.6$ ) (Figure 1). The 5- and 10-year DFS were 63.6 and $39.8 \%$ respectively. The 5 -year DFS was $77 \%$ for the patients with TRG3 -4 and $58 \%$ for the patients with TRG0-2 (HR, 0.36; 95\% CI: $0.18-0.74 ; P=0.005$; Figure 2). The 5-year DFS was 64.2 and $62.2 \%$ for patients with low vs high EGFR/nuclei respectively (HR, 0.99; 95\% CI: $0.51-1.94 ; P=0.99$ ); 67.2 and $51.1 \%$ for patients with low vs high CEP7 polisomy respectively (HR, $1.43 ; 95 \%$ CI: $0.78-2.60 ; P=0.24$ ); 64.7 and $61.3 \%$ for patients with wild-type $v s$ mutated KRAS respectively (HR, 0.94; 95\% CI: $0.49-1.83 ; P=0.86)$.

Median OS was 9.0 years (range $0.26-10.6$ ) (Figure 3). At 5 and 10 years OS rates were 71.5 and $44.9 \%$ respectively. At 5 years, OS rates were 89.7 and $64.8 \%$ for the patients who achieved a TRG3-4 and patients with TRG $0-2$ respectively (HR, 0.26; 95\% CI: $0.10-0.66 ; P=0.005$ ) (Figure 4); $72.3 \%$ for both wild-type and mutated KRAS patients; 71.0 and $76.2 \%$ for patients with low $v s$ high EGFR/nuclei ratio respectively (HR, 1.13; 95\% CI: $0.54-2.39$; $P=0.74) ; 75.3$ and $60.9 \%$ for the patients with low $v s$ high CEP7 polisomy respectively (HR, 1.83 ; $95 \% \mathrm{CI}$ : $0.94-3.57 ; P=0.07$ ). 
Table 2 EGFR gene copy number, KRAS status, pathological response and downstaging

\begin{tabular}{|c|c|c|c|c|c|c|c|c|c|}
\hline & \multicolumn{2}{|c|}{ EGFR/nuclei ratio } & \multirow[b]{2}{*}{$P$-value } & \multicolumn{2}{|c|}{ CEP7 polisomy } & \multirow[b]{2}{*}{$P$-value } & \multicolumn{2}{|c|}{ KRAS status } & \multirow[b]{2}{*}{$P$-value } \\
\hline & $<\mathbf{2 . 9}$ & $\geqslant 2.9$ & & $<\mathbf{5 0} \%$ & $\geqslant \mathbf{5 0} \%$ & & Wild type & Mutated & \\
\hline Assessable patients, $n$ & 113 & 27 & & 110 & 30 & & 114 & 27 & \\
\hline TRG $4, n(\%)$ & $15(13.3)$ & $6(22.2)$ & 0.19 & $14(12.7)$ & $7(23.3)$ & 0.13 & $19(16.7)$ & $2(7.4)$ & 0.18 \\
\hline TRG 3-4, n (\%) & $36(31.9)$ & $9(33.3)$ & 0.53 & $36(32.7)$ & $9(30.0)$ & 0.48 & $40(35.1)$ & $51(8.5)$ & 0.07 \\
\hline Downstaging, n (\%) & $65(59.6)$ & $19(65.5)$ & 0.36 & $68(64.8)$ & $16(48.5)$ & 0.07 & $69(62.2)$ & $16(57.1)$ & 0.39 \\
\hline
\end{tabular}

Abbreviations: $E G F R=$ epidermal growth factor receptor; TRG $=$ tumour regression grade.

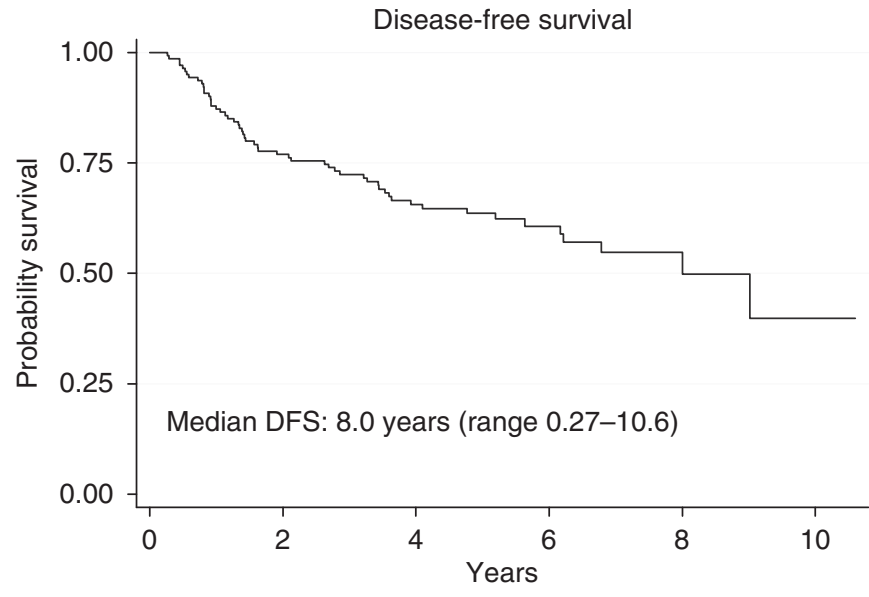

Figure I Disease-free survival of entire group of patients.

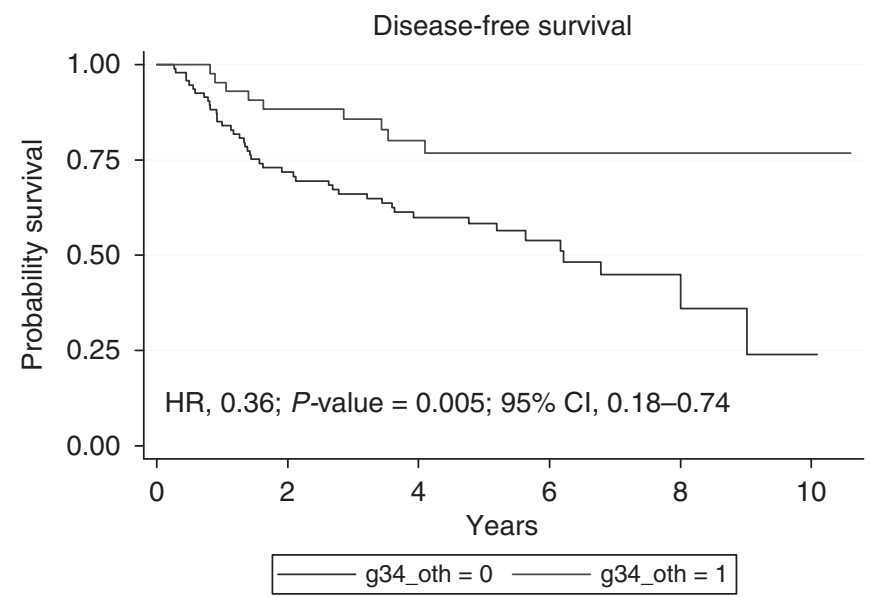

Figure 2 Disease-free survival according to the tumour regression grade.

\section{DISCUSSION}

Epidermal growth factor receptor expression has been shown to be associated with disease recurrence and poor survival in colon cancer (Iqbal and Lenz, 2001; Watanabe et al, 2001; Galizia et al, 2006). Moreover, the predictive role of EGFR expression on tumour response and locoregional recurrence has been extensively investigated in patients with LARC treated with preoperative chemoradiation therapy (Giralt et al, 2002; Azria et al, 2005). All the data show that EGFR expression, evaluated by IHC, is a

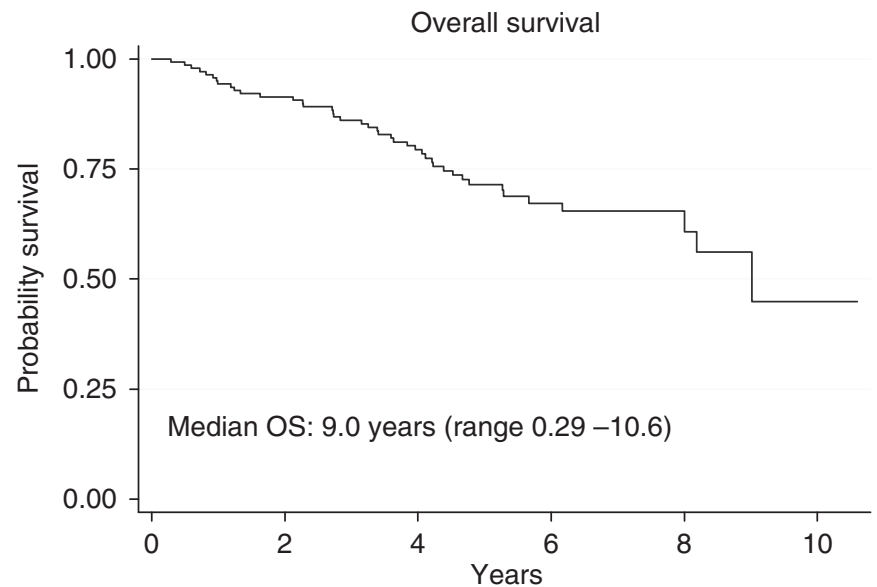

Figure 3 Overall survival of the entire group of patients.

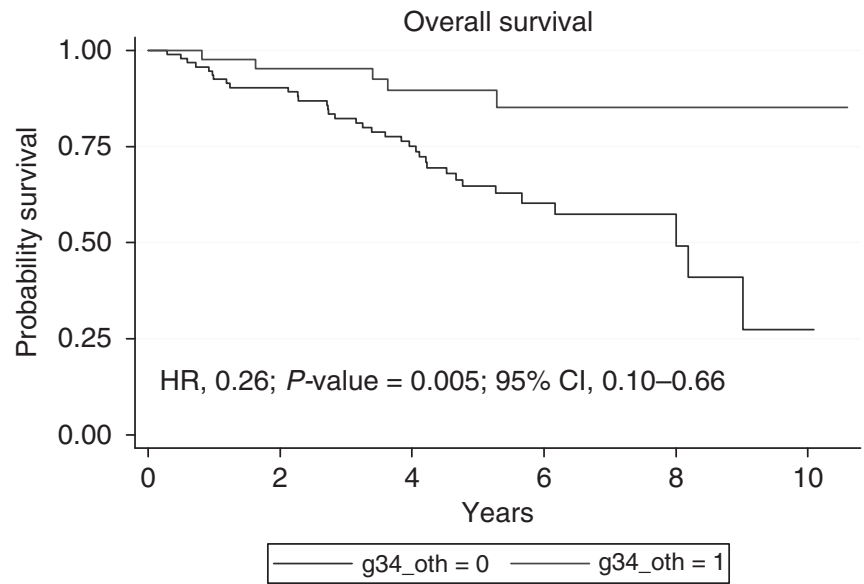

Figure 4 Overall survival according to the tumour regression grade.

predictive factor for poor tumour response and local recurrence after preoperative chemoradiation therapy and curative surgery for rectal cancer. Moreover Giralt et al (2005) and Li et al (2006) reported that baseline EGFR expression is an independent prognostic factor for DFS and distant metastasis-free survival. We recently analysed patients with LARC treated with preoperative CTRT and we were unable to confirm that baseline EGFR expression evaluated by IHC is a predictive factor for response as well as prognostic factor on survival; on the contrary, EGFR expression by IHC on residual tumour after preoperative 
chemoradiation is an independent poor prognostic factor for disease recurrence (Bertolini et al, 2007). Possible explanation for these discrepancies can be unreliable techniques of immunostaining and scoring, heterogeneity of EGFR expression, and high and low affinity of EGFR. Moreover polymorphism of EGFR has been shown to predict tumour response to CTRT and locoregional tumour recurrence after CTRT (Zhang et al, 2005; Spindler et al, 2006).

In this study we show that EGFR GCN is not predictive of response to preoperative chemoradiation therapy and is not a prognostic factor for DFS and OS. Interestingly, we had previously reported that high EGFR GCN is predictive of TRG3-4 in patients treated with chemoradiation in combination with cetuximab (Bengala et al, 2009). These evidences are not in contrast because while EGFR GCN may not have a prognostic value it can be a possible predictive factor of response to anti-EGFR monoclonal antibody cetuximab.

KRAS mutation status has been extensively studied as a predictive factor of resistance to anti-EGFR monoclonal antibodies. In our study, KRAS mutation status is not a predictive factor for neither pathologic response nor downstaging, although the rate of pathological regression grade $3-4$ was 35.1 vs $18.5 \%$ in patients with wild-type and mutated KRAS status respectively $(P=0.07)$. Moreover, KRAS status did not predict DFS and OS.

Two large prospective studies conducted in stage II-III colon cancer (Roth et al, 2010) and in advanced colorectal cancer (Bokemeyer et al, 2009; Van Cutsem et al, 2009) have shown that KRAS mutation is not a prognostic factor. Conversely, two large collaborative studies, the RASCAL trials, have reported an

\section{REFERENCES}

Andreyev HJ, Norman AR, Cunningham D, Oates JR, Clarke PA (1998) Kirsten ras mutations in patients with colorectal cancer: the multicenter 'RASCAL' study. I Natl Cancer Inst 90: 675-684

Andreyev HJ, Norman AR, Cunningham D, Oates J, Dix BR, Iacopetta BJ, Young J, Walsh T, Ward R, Hawkins N, Beranek M, Jandik P, Benamouzig R, Jullian E, Laurent-Puig P, Olschwang S, Muller O, Hoffmann I, Rabes HM, Zietz C, Troungos C, Valavanis C, Yuen ST, Ho JW, Croke CT, O'Donoghue DP, Giaretti W, Rapallo A, Russo A, Bazan V, Tanaka M, Omura K, Azuma T, Ohkusa T, Fujimori T, Ono Y, Pauly M, Faber C, Glaesener R, de Goeij AF, Arends JW, Andersen SN, Lövig T, Breivik J, Gaudernack G, Clausen OP, De Angelis PD, Meling GI, Rognum TO, Smith R, Goh HS, Font A, Rosell R, Sun XF, Zhang H, Benhattar J, Losi L, Lee JQ, Wang ST, Clarke PA, Bell S, Quirke P, Bubb VJ, Piris J, Cruickshank NR, Morton D, Fox JC, Al-Mulla F, Lees N, Hall CN, Snary D, Wilkinson K, Dillon D, Costa J, Pricolo VE, Finkelstein SD, Thebo JS, Senagore AJ, Halter SA, Wadler S, Malik S, Krtolica K, Urosevic N (2001) Kirsten ras mutations in patients with colorectal cancer: the 'RASCAL II' study. Br J Cancer 85: 692-696

Atkins D, Reiffen KA, Tegtmeier CL, Winther H, Bonato MS, Störkel S (2004) Immunohistochemical detection of EGFR in paraffinembedded tumor tissue: variations in staining intensity due to choice of fixative and storage time of tissue sections. J Histochem Cytochem 52: $893-901$

Azria D, Bibeau F, Barbier N, Zouhair A, Lemanski C, Rouanet P, Ychou M, Senesse P, Ozsahin M, Pèlegrin A, Dubois JB, Thèzenas S (2005) Prognostic impact of epidermal growth factor receptor (EGFR) expression on loco-regional recurrence after preoperative radiotherapy in rectal cancer. BMC Cancer 5: $62-71$

Bengala C, Bettelli S, Bertolini F, Salvi S, Chiara S, Sonaglio C, Losi L, Bigiani N, Sartori G, Dealis C, Malavasi N, D’Amico R, Luppi G, Gatteschi B, Maiorana A, Conte PF (2009) Epidermal growth factor receptor gene copy number, K-ras mutation and pathological response to preoperative cetuximab, 5-FU and radiation therapy in locally advanced rectal cancer. Ann Oncol 20: $469-474$

Bertolini F, Bengala C, Losi L, Pagano M, Iachetta F, Dealis C, Jovic G, Depenni R, Zironi S, Falchi AM, Luppi G, Conte PF (2007) Prognostic and predictive value of baseline and post treatment molecular marker increased risk of recurrence and death in patients with colon cancer and KRAS mutation (Andreyev et al, 1998, 2001). In the study by Roth et al (2010), tumour specimens were prospectively collected and analysed in a central laboratory, whereas in the RASCAL trials the specimens were retrospectively analysed in local laboratories and this could explain the contradictory results. Moreover, the second RASCAL trial reported a poor outcome only for a small subset of patients bearing a G12V mutation raising the question on the possible prognostic relevance of specific KRAS mutations (Andreyev et al, 2001). Unfortunately the study by Roth et al did not have a sufficient statistical power to detect a possible prognostic role of different KRAS mutations. Differences in patient population (colorectal $v s$ locally advanced rectal), treatments (chemotherapy $v s$ chemoradiation) and sample sizes might account for the inconsistency of available data on prognostic role of KRAS mutation across these studies.

In conclusion, our data show that EGFR GCN and KRAS mutation status are neither predictive nor prognostic factors for pathological tumour response and DFS in LARC patients treated with preoperative chemoradiation. On the basis of these data, KRAS status should not be used to select therapies other than anti EGFR antibodies.

\section{ACKNOWLEDGEMENTS}

This study was supported in part by a grant of the Emilia Romagna Region (DGR-ER-2242-2007) for University-Region Project.

expression in locally advanced rectal cancer treated with neoadjuvant chemoradiotherapy. Int J Radiat Oncol Biol Phys 68: 1455-1461

Bokemeyer C, Bondarenko I, Makhson A, Hartmann JT, Aparicio J, de Braud F, Donea S, Ludwig H, Schuch G, Stroh C, Loos AH, Zubel A, Koralewski P (2009) Fluorouracil, leucovorin, and oxaliplatin with and without cetuximab in the first-line treatment of metastatic colorectal cancer. J Clin Oncol 27: 663-671

Cappuzzo F, Finocchiaro G, Rossi E, Jänne PA, Carnaghi C, Calandri C, Bencardino K, Ligorio C, Ciardiello F, Pressiani T, Destro A, Roncalli M, Crino L, Franklin WA, Santoro A, Varella-Garcia M (2008) EGFR FISH assay predicts for response to cetuximab in chemotherapy refractory colorectal cancer patients. Ann Oncol 19: 717-723

Chung KY, Shia J, Kemeny NE, Shah M, Schwartz GK, Tse A, Hamilton A, Pan D, Schrag D, Schwartz L, Klimstra DS, Fridman D, Kelsen DP, Saltz LB (2005) Cetuximab shows activity in colorectal cancer patients with tumors that do not express the epidermal growth factor receptor by immunohistochemistry. J Clin Oncol 23: $1803-1810$

Dworak O, Keilholz L, Hoffmann A (1997) Pathological features of rectal cancer after preoperative radiochemotherapy. Int J Colorectal Dis 12: $19-23$

Galizia G, Lieto E, Ferraraccio F, De Vita F, Castellano P, Orditura M, Imperatore V, La Mura A, La Manna G, Pinto M, Catalano G, Pignatelli C, Ciardiello F (2006) Prognostic significance of epidermal growth factor receptor expression in colon cancer patients undergoing curative surgery. Ann Surg Oncol 13: $823-835$

Gavioli M, Luppi G, Losi L, Bertolini F, Santantonio M, Falchi AM, D'Amico R, Conte PF, Natalini G (2005) Incidence and clinical impact of sterilized disease and minimal residual disease after preoperative radiochemotherapy for rectal cancer. Dis Colon Rectum 48: 1851-1857

Giralt J, Eraso A, Armengol M, Rosselló J, Majó J, Ares C, Espin E, Benavente S, de Torres I (2002) Epidermal growth factor receptor is a predictor of tumor response in locally advanced rectal cancer patients treated with preoperative radiotherapy. Int J Radiat Oncol Biol Phys 54: 1460 - 1465

Giralt J, de las Heras M, Cerezo L, Eraso A, Hermosilla E, Velez D, Lujan J, Espin E, Rosello J, Majó J, Benavente S, Armengol M, de Torres I, Grupo Español de Investigacion Clinica en Oncologia Radioterápica (GICOR) 
(2005) The expression of epidermal growth factor receptor results in a worse prognosis for patients with rectal cancer treated with preoperative radiotherapy: a multicenter, retrospective analysis. Radiother Oncol 74: $101-108$

Iqbal S, Lenz HJ (2001) Determinants of prognosis and response to therapy in colorectal cancer. Curr Oncol Rep 3: $102-108$

Kim J-S, Kim J-M, Li S, Yoon WH, Song KS, Kim KH, Yeo SG, Nam JS, Cho MJ (2006) Epidermal growth factor receptor as a predictor of tumor downstaging in locally advanced rectal cancer patients treated with preoperative chemoradiotherapy. Int J Radiat Oncol Biol Phys 66: $195-200$

Li S, Kim JS, Kim JM, Cho MJ, Yoon WH, Song KS, Yeo SG, Kim JS (2006) Epidermal growth factor receptor as a prognostic factor in locally advanced rectal-cancer patients treated with preoperative chemoradiation. Int J Radiat Oncol Biol Phys 65: 705-712

Moroni M, Veronese S, Benvenuti S, Marrapese G, Sartore-Bianchi A Di Nicolantonio F, Gambacorta M, Siena S, Bardelli A (2005) Gene copy number for epidermal growth factor receptor (EGFR) and clinical response to antiEGFR treatment in colorectal cancer: a cohort study. Lancet Oncol 6: 279-286

Rodel C, Martus P, Papadoupolos T, Füzesi L, Klimpfinger M, Fietkau R, Liersch T, Hohenberger W, Raab R, Sauer R, Wittekind C (2005) Prognostic significance of tumor regression after preoperative chemoradiotherapy for rectal cancer. J Clin Oncol 23: 8688-8696

Roth AD, Tejpar S, Delorenzi M, Yan P, Fiocca R, Klingbiel D, Dietrich D, Biesmans B, Bodoky G, Barone C, Aranda E, Nordlinger B, Cisar L,
Labianca R, Cunningham D, Van Cutsem E, Bosman F (2010) Prognostic role of KRAS and BRAF in stage II and III resected colon cancer: results of the translational study on the PETACC-3, EORTC 40993, SAKK 60-00 trial. J Clin Oncol 28: $466-474$

Shia J, Klimstra DS, Li AR, Qin J, Saltz L, Teruya-Feldstein J, Akram M, Chung KY, Yao D, Paty PB, Gerald W, Chen B (2005) Epidermal growth factor receptor expression and gene amplification in colorectal carcinoma: an immunohistochemical and chromogenic in situ hybridization study. Mod Pathol 18: $1350-1356$

Spindler KL, Nielsen JN, Lindebjerg J, Brandslund I, Jakobsen A (2006) Prediction of response to chemoradiotherapy in rectal cancer by a gene polymorphism in the epidermal growth factor receptor promoter region. Int J Radiat Oncol Biol Phys 66: 195-200

Van Cutsem E, Köhne C-H, Hitre E, Zaluski J, Chang Chien CR, Makhson A, D’Haens G, Pintér T, Lim R, Bodoky G, Roh JK, Folprecht G, Ruff P, Stroh C, Tejpar S, Schlichting M, Nippgen J, Rougier P (2009) Cetuximab and chemotherapy as initial treatment for metastatic colorectal cancer. $N$ Engl J Med 360: 1408-1417

Watanabe T, Wu TT, Catalano PJ, Ueki T, Satriano R, Haller DG, Benson 3rd AB, Hamilton SR (2001) Molecular predictors of survival after adjuvant chemotherapy for colon cancer. $N$ Engl J Med 344: 1196-1206

Zhang W, Park DJ, Lu B, Yang DY, Gordon M, Groshen S, Yun J, Press OA, Vallböhmer D, Rhodes K, Lenz HJ (2005) Epidermal growth factor receptor gene polymorphisms predict pelvic recurrence in patients with rectal cancer treated with chemoradiation. Clin Cancer Res 11: $600-605$ 